\title{
Comparison of Charging and Discharging Period Analysis of Phase Change Materials-Paraffin Wax and Myristic Acid
}

\author{
Ajay M Nair" and P Vinod Kumar Naidu** \\ \#Department of Mechanical Engineering, Toc H Institute of Science and Technology, Ernakulam, India \\ ${ }^{\wedge}$ Department of Mechanical Engineering, Chaitanya Bharathi Institute of Technology, Hyderabad, India
}

Received 01 Nov 2017, Accepted 01 Jan 2018, Available online 07 Jan 2018, Vol.8, No.1 (Jan/Feb 2018)

\begin{abstract}
The present work is focussed on the experimental study of a PCM storage unit for thermal energy storage. Thermal energy storage systems are temporary storage of the thermal energy at high or low temperature and is a very essential tool to reduce the mismatch between supply and demand of energy. These also play very important role in energy conservation. In this experiments two PCM's Paraffin wax and Myristic acid are compared by analysing their charging and discharging (storing) period, which is done in a simple and economically fabricated experimental set up. It is found that Myristic acid took only 2 hours and 25 minutes for complete charging while it was around 3 hours and 7 minutes for Paraffin wax. During storage period analysis it is evident that the Myristic acid stored heat better than Paraffin. However the drop in temperature of Myristic acid was just $7^{\circ} \mathrm{C}$ in 8 hours whereas it was around $12^{\circ} \mathrm{C}$ for Paraffin wax in the same time period.
\end{abstract}

Keywords: Phase Change Materials (PCMs), Chagrining, Discharging, Storage period

\section{Introduction}

Global energy crisis is increasing as the conventional fossil fuels reserves are running out while at the same the energy demand is creeping up and these fossil fuel results in causing the adverse effects on the environment like global warming, melting of polar ice etc. Most of the scientists across the agreed that solar energy is best alternative to the conventional fossil fuels as it is abundantly available across the earth and do not cause pollution to the environment but it has limitation like intermittent nature, as they are not available all the time. This intermittent problem can be solved by thermal energy storage. PCM's are the best option for the thermal energy storage. The PCM may charge and discharge large amount of heat during melting and discharging at nearly isothermal nature

Antonio Lecuona et al have reviewed issues on portable solar cooker made up of two conventional coaxial cylindrical cooking pots and intermediate space id filled with phase change materials namely technical grade Paraffin as first case and erythritol as second case and the results of showed that the hot cooked food kept inside the insulated box allows to retained heat till next day morning. Hussain $\mathrm{H}$. Al-Kayiem et al presented analyzes of a flat plate solar collector integrated with built-in thermal energy storage and

*Corresponding author's ORCID ID: 0000-0002-5835-4608 DOI: https://doi.org/10.14741/ijcet.v8i01.10886 various case have been investigated namely without phase change material, phase change material (Paraffin wax) and nanocomposites of phase change material (nanocomposite of paraffin wax with $1.0 \mathrm{wt} \%$ of $20-\mathrm{nm}$ nano $\mathrm{Cu}$ particles) at $10^{\circ}, 20^{\circ}$, and $30^{\circ}$ inclination angles of each case. $10^{\circ}$ inclination angle was found to be the best operational condition with efficiencies of 52.0, $51.1 \%$ and, $47.6 \%$,for the cases with $\mathrm{Cu}$-phase change material nanocomposite, with phase change material and without phase change material and there is not enhancement of the system using copper phase change material compared to the system with phase change material.

Yongcai Li et al experimentally investigated the thermal performance of a phase change material (PCM) based solar chimney under a laboratory condition with three different heat fluxes of $500 \mathrm{~W} / \mathrm{m} 2,600 \mathrm{~W} / \mathrm{m} 2$ and $700 \mathrm{~W} / \mathrm{m} 2$ and fixed the constant charging of 7 hours and 10 minutes and absorbed the status of phase change material during this period and the air flow rates varies corresponding to the absorber temperature unlike this the outlet average temperature is lowest for $700 \mathrm{~W} / \mathrm{m} 2$ case The peak thermal efficiencies of the solar chimney are observed to be about $80 \%$ for all cases at the early ventilation period. $500 \mathrm{~W} / \mathrm{m} 2$ however drives the highest minimum efficiency of 63\%. Mónica Delgado et al, experimentally analysed thermal energy storage system in terms of volumetric energy density and heat transfer rate, thermal energy storage is of $46 \mathrm{~L}$ commercial tank 
consist of a helical coil heat exchanger impress in a low cost phase change material emulsion having a range of phase change temperature between $30^{\circ} \mathrm{C}$ and $50^{\circ} \mathrm{C}$ and solid content is about $60 \%$ with average particle size of $1 \mu \mathrm{m}$ and concluded that heat transfer coefficient is around 2-6 times higher for the phase change material emulsion compare to that of conventional latent systems and also an energy density of 34\% higher for the phase change material emulsion. A. Hasan et al developed a photovoltaic-phase change material (PV$\mathrm{PCM}$ ) system to reduce photovoltaic temperature dependent power loss. It has been evaluated with two phase change materials: a salt hydrate ( $\mathrm{CaCl} 2$ _6 20 ) and a eutectic mixture of fatty acids, (capric acidpalmitic acid in different sites and both Both the photovoltaic-phase change material maintained lower photovoltaic panel temperature than the reference photovoltaic panel by maintaining the lower photovoltaic temperatures effected photovoltaic power loss and increased PV conversion efficiencies. Ahmed A.A. Attia et al experimental studied the effects of adding Al203 nanoparticles to distilled water and aqua ethylene glycol solution at different volume fraction concentration up to $1 \%$ for different inlet temperature volume flow rates on the solidified mass fraction, surface heat flux and complete solidification time, was performed and concluded the adding nano particle to the phase change material improved the performance of cool storage system then adding to the heat transfer fluid alone A.E. Kabeel et al, compared the experimentally studied of the productivity of a solar still, one incorporated with the phase change material and other the conventional solar still desalination system the results showed that the daily freshwater productivity for the solar still which is incorporated with the phase change material is higher than conventional solar still i.e. $4.51 \mathrm{~L} / \mathrm{m}^{2}$ and which is about $67.18 \%$ higher

\section{Experimental Setup}

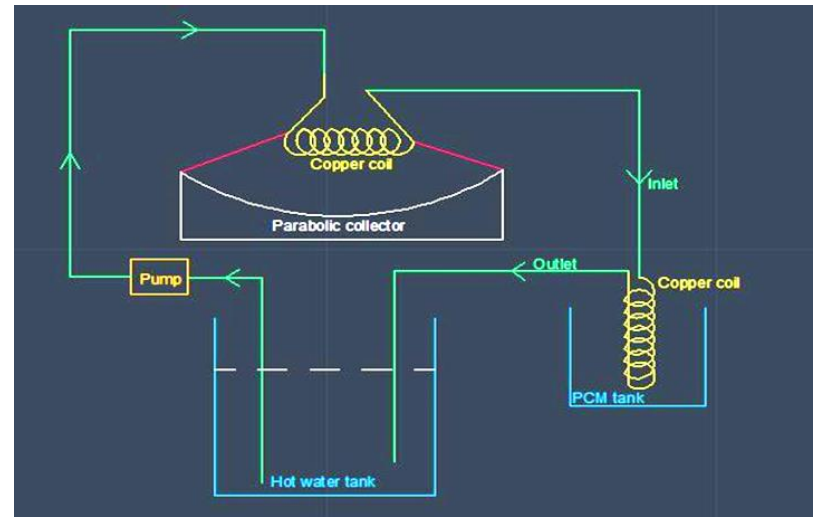

Fig 1.Schematic diagram of the experimental setup

To analysis the thermal performance of two phase change material i.e. Paraffin wax and Myristic acid a simple and economical experimental setup has been constructed and the experimental setup consist insulated hot water bath, which is rectangular metallic tank having multi-layer of insulation in order to reduce the heat loss, initially it is painted with black spray paint over it cardboard is placed, next layer of insulation is thermocol with aluminium foil and cardboard is placed over, it at last black paper layer were used.

A water pump (model star RS25/6 WILO Company Germany, capacity $800-3400 \mathrm{lph}$, head of 2-5 m) is connected to the hot water bath. Test section consisting of helical copper heat exchanger made of $1 / 4$ inch copper tube having helical outer diameter of $8 \mathrm{~cm}$ and length of $10 \mathrm{~cm}$ which is immersed in the PCM (500gm of each Paraffin wax and Myristic acid powder) in PCM container of borosilicate glass of one litre capacity and this test section is placed in an insulated box which is insulated similar to that of hot water bath and two T type thermocouples are placed at different locations in the PCM container to record the temperature of PCM at different interval of charging time and the parabolic solar concentrator which is made of wooden base and aluminium sheets as reflector with focal length of $50 \mathrm{~cm}$ and at the focal point a three concentric coil of $3 / 8$ inch diameter copper tube is placed so that the solar radiations are reflected over it.
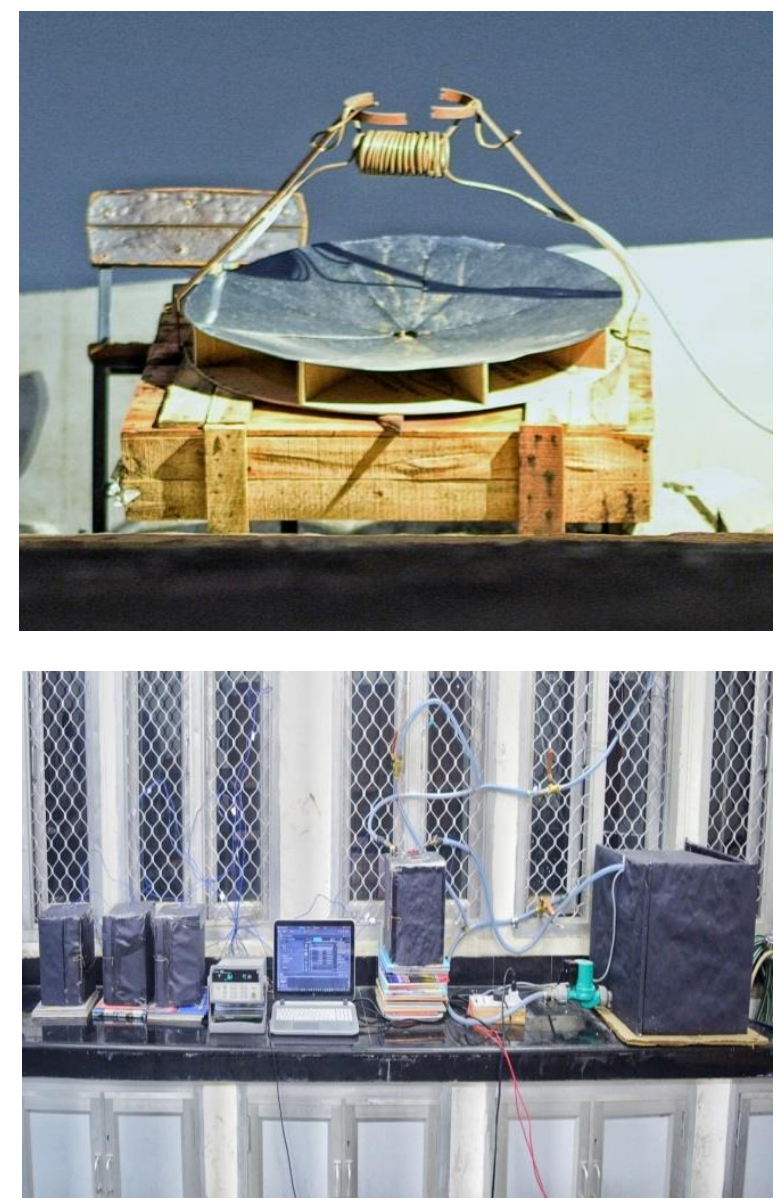

Fig 3 Photograph of the experimental set up

Initially water gets heated at solar parabolic concentrator and then it flows to the hot water bath 
from there it pump to the section test through water pump, in the test section the heat is flown from hot water in the heat exchanger to the PCM which gets charged then flows back to the solar parabolic concentrator. Once PCM is get fully charged the PCM is taken out from test section and placed in the insulation box which is made as that of test section insulation box where discharge analysis of PCM is done with help of two thermocouples placed in the PCM container and all these thermocouples are connected to a data acquisition system (Agilent 34972A LXI).

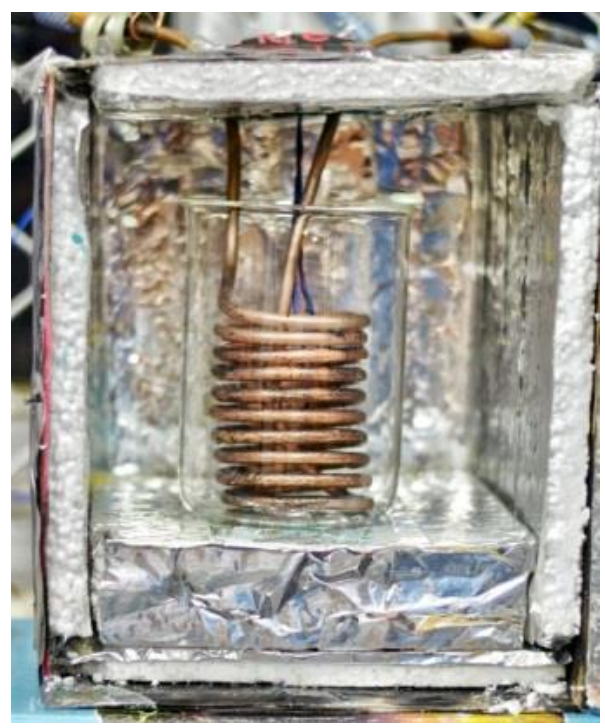

Fig 4 Insulated charging box with copper coil heat exchanger and PCM container

Table1 Properties of Paraffin Wax and Myristic acid

\begin{tabular}{|c|c|c|c|c|}
\hline 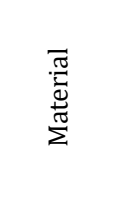 & 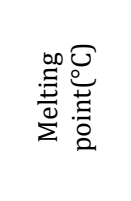 & 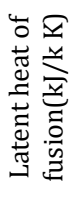 & 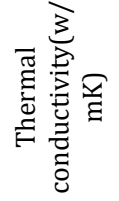 & 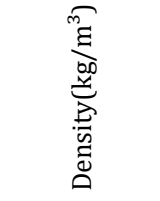 \\
\hline $\begin{array}{l}\text { Paraffin } \\
\text { Wax }\end{array}$ & $58-60^{\circ} \mathrm{C}$ & 189 & $0.21(\mathrm{~s})$ & $\begin{array}{l}795\left(1,70^{\circ} \mathrm{C}\right) \\
920\left(\mathrm{~s}, 20^{\circ} \mathrm{C}\right)\end{array}$ \\
\hline $\begin{array}{c}\text { Myristic } \\
\text { acid }\end{array}$ & $52-54^{\circ} \mathrm{C}$ & 204 & 0.17 (s) & $\begin{array}{l}861\left(\mathrm{l}, 55^{\circ} \mathrm{C}\right) \\
990\left(\mathrm{~s}, 24^{\circ} \mathrm{C}\right)\end{array}$ \\
\hline
\end{tabular}

\section{Results and Discussions}

Different stages during charging of Myristic acid and Paraffin wax are shown in 3.a to 3.c and 3.d to 3.e respectively. From the experimental analysis of Paraffin wax and Myristic acid it is evident that charging period duration of Paraffin wax is 3 hours 7 mins and that of Myristic acid is 2hours 25min. The graph 4.a and 4.b represents the charging time vs temperature of Myristic acid and Paraffin wax respectively.

From the graph 4.c and 4.d and experimental analysis it is clear that the temperature of molten metal had dropped by $12^{\circ} \mathrm{C}$ in 8 hours of storing where as in case of Myristic acid the drop in temperature was found to be nearly $7^{\circ} \mathrm{C}$ in 8 hours, which is very promising?

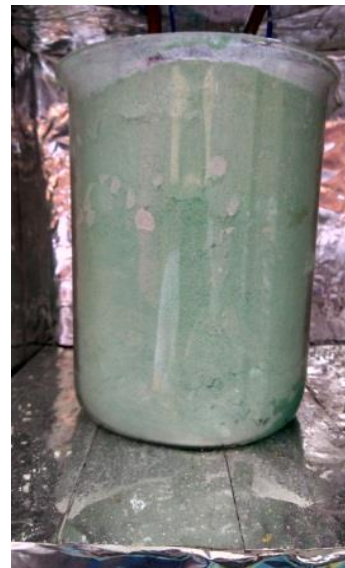

(a)

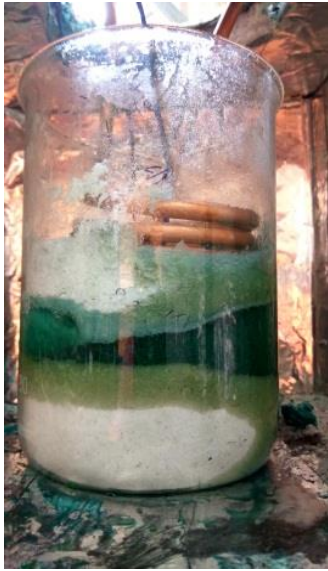

(b)

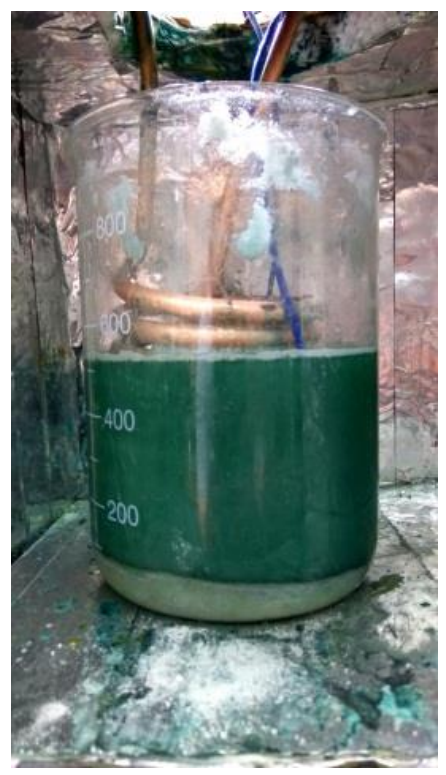

(c)

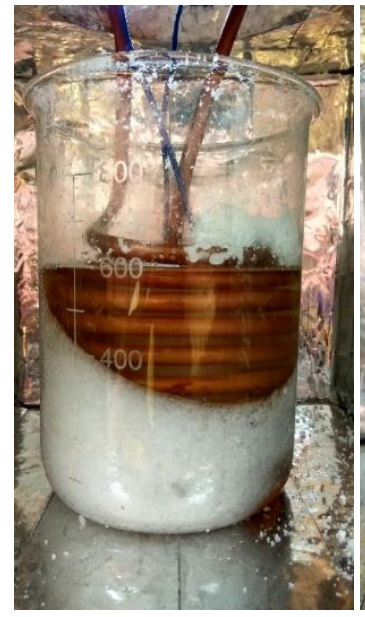

(d)

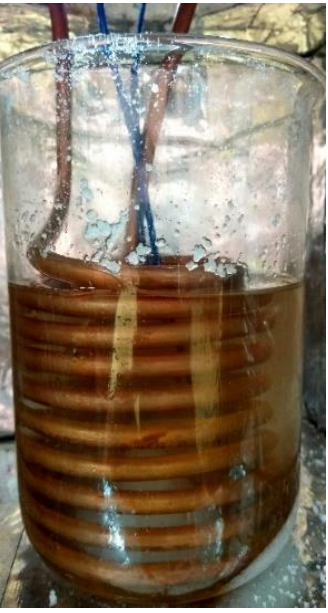

(e)
Fig3 (a)-(c) Stages during charging of Myristic acid (d)- (e) Stages during charging of Paraffin wax 


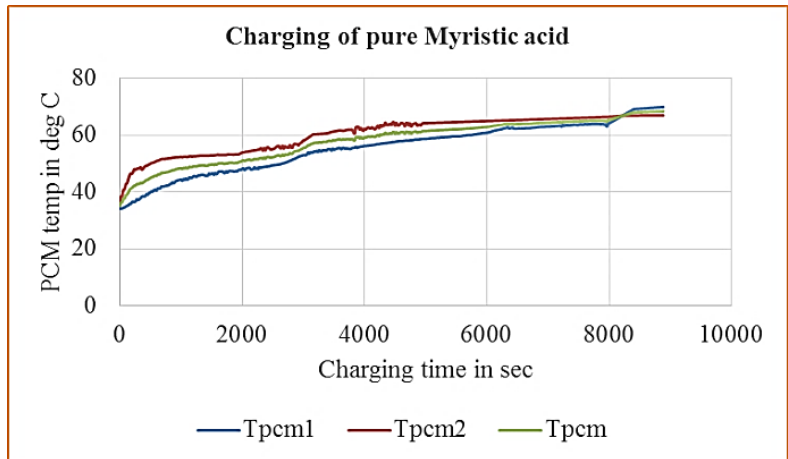

(a)

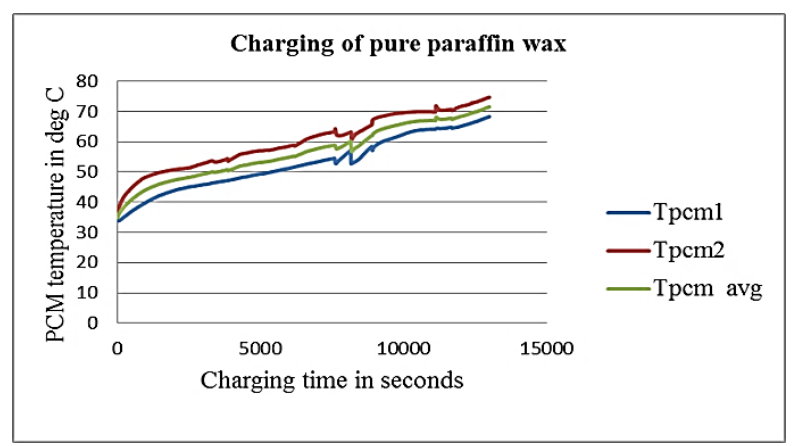

(b)

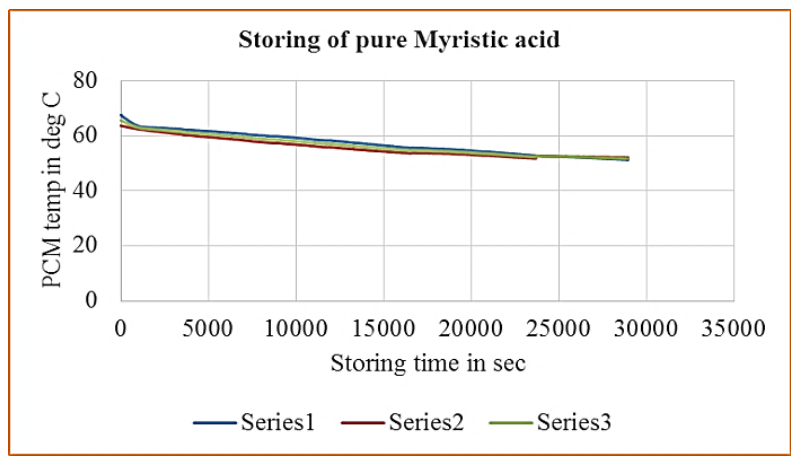

(c)

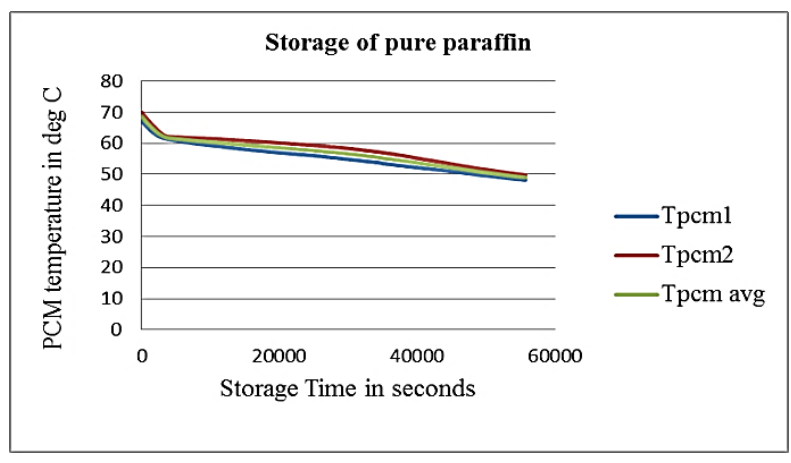

(d)

Fig 4.a Charging time vs Temp of Pure Myristic acid 4. b Charging time vs Temp of Paraffin wax 4. c Storing time vs Temp of Myristic acid 4. d Storing time vs Temp of Paraffin wax

\section{Conclusion}

From the charging and storing period analysis of Paraffin wax and Myristic acid it is clear that

1) Myristic acid undergone complete melting much faster than Paraffin wax thogh their melting range is nearly the same.

2) The storing or discharging period analysis indicates that in 8 hours nearly $7^{\circ} \mathrm{C}$ temperature drop was recorded for Myristic acid whereas for Paraffin it was around $12^{\circ} \mathrm{C}$. it is a clear indication of higher thermal storage capacity of Myristic acid though both the samples has nearly same charging range.

3) Further analysis indicated that Paraffin wax lost its heat quickly as compared to Myristic acid. For Myristic acid even after 10 hours of discharging also there was no much temperature change.

4) So Myristic acid can be a good substitute for Paraffin where more storing time is required

\section{References}

Antonio Lecuona, José-Ignacio Nogueira, Rubén Ventas, María-del-Carmen Rodríguez-Hidalgo, Mathieu Legrand (2013),Solar cooker of the portable parabolic type incorporating heat storage based on PCM, Elsevier, Applied Energy 111,1136-1146

Hussain H. Al-Kayiem, Saw C. Lin (2014), Performance evaluation of a solar water heater integrated with a PCM nanocomposite TES at various inclinations, Elsevier, Science Direct Solar Energy 109, 82-92

Yongcai Li, Shuli Liu (2014) Experimental study on thermal performance of a solar chimney combined with PCM, Elsevier, Applied Energy 114, 172-178

Mónica Delgado đ, Ana Lázaro, Javier Mazo, Conchita Peñalosa, Pablo Dolado, Belén Zalba (2015), Experimental analysis of a low cost phase change material emulsion for its use as thermal storage system, Elsevier, Science Direct, Energy Conversion and Management 106, 201-212

A. Hasan, S.J. McCormack, M.J. Huang, J. Sarwar, B. (2015)Norton Increased photovoltaic performance through temperature regulation by phase change materials: Materials comparison in different climates, Elsevier, Science Direct, Solar Energy 115, 264-276

Ahmed A.A. Attia, Ahmed A. Altohamy, M.F. Abd Rabbo, R.Y. Sakr(2016), Comparative study on AL203 nanoparticle addition on cool storage system performance, Elsevier, Applied Thermal Engineering 94, 449-457

A.E. Kabeel, Mohamed Abdelgaied (2016), Improving the performance of solar still by using PCM as a thermal storage medium under Egyptian conditions, Elsevier, Science Direct, Desalination $383,22-28$ 